\title{
REPERCUSSÕES DAS POLÍTICAS MULTICULTURAIS NA EDUCAÇÃ̃O
}

\author{
Alice Miriam HaPp Botler ${ }^{* *}$
}

\begin{abstract}
RESUMO: A pesquisa analisou as implicações das políticas multiculturais na educação e na escola, bem como as concepções e experiências relacionadas. Apresenta resultados parciais de investigação pautada em estudo de caso numa escola pública de ensino médio canadense, considerada, em sua realidade, de elevado padrão de qualidade de vida e direitos humanos. $\mathrm{O}$ estudo serve como referência analítica à realidade educacional brasileira. Destacamos as diferentes noções de estudante em situação de risco, como resultado prático das políticas educacionais multiculturais. Entre as considerações a respeito, a categoria estudante em situação de risco denota a exclusão social como repercussão destas políticas sob diferentes prismas, ora no Canadá com sentido afirmativo de mistura racial e cultural, ora no Brasil, com sentido de diferenciação social.
\end{abstract}

Palavras-chave: Estudante em situação de risco. Ensino médio. Educação inclusiva. Política educacional. Multiculturalismo.

\section{EFFECTS OF MULTICULTURAL POLITICS IN EDUCATION}

ABSTRACT: The research aimed to analyze the implications of multicultural politics in education and school as well as identify related conceptions and experiences. Presents partial results of a study case in a Canadian public high school, considered in terms of quality of life and human rights. The study case is used as a reference to analyze the Brazilian education where the different notions of student at risk were highlight as a practical result of the multicultural education policy. Among the results we consider that this category denotes the social exclusion as an impact of the educational policies from different perspectives, sometimes in Canada with an affirmative sense of racial and cultural mix, or in Brazil as a social segregation.

Key words: Student at risk. High school. Inclusive education. Educational policy. Multiculturalism.

\footnotetext{
* Pesquisa realizada com o apoio da Capes/MEC.

* Doutora em Sociologia e professora do Departamento de Administração Escolar e Planejamento Educacional e do Programa de Pós-Graduação em Educação da Universidade Federal de Pernambuco (Ufpe). E-mail: alicebotler@hotmail.com
} 


\section{EfFEtS DES POLITIQUES MULTiCULTURELLES D'EDUCATION}

RÉSUMÉ: La recherche a analysé les implications des politiques multiculturelles dans l'éducation et l'école ainsi que leurs conceptions et expériences. Cet article présente des résultats partiels de la recherche portant sur une étude de cas dans un lycée public canadien, reputé pour son haut standard de qualité de vie et les droits humains. L'étude sert de référence d'analyse à la réalité éducationnelle brésilienne. Nous mettons en évidence les différentes notions d'élèves à risque, comme un résultat pratique des politiques de l'éducation multiculturelles. Parmi les considérations sur la catégorie des étudiants à risque døexclusion sociale, tout indique l'impact de ces politiques à partir de perspectives différentes, soit au Canada, avec le mélange racial et culturel entendu au sens affirmatif, soit au Brésil par la différenciation sociale.

Mots-clés: Les élèves à risque. L'école secondaire. L'éducation inclusive. La politique éducative. Le multiculturalisme.

\section{Introdução}

$\sqrt{1}$ ste artigo deriva da análise de resultados de uma pesquisa que objetiva identificar implicações das políticas multiculturais na educação e na escola, bem como conhecer as concepções e experiências relacionadas. Apresenta resultados parciais de investigação pautada em estudo de caso numa escola pública de ensino médio canadense, considerada, em sua realidade, de elevado padrão de qualidade de vida e de respeito aos direitos humanos, a partir de uma leitura descontinuista da história (Malet, 2004) que toma como objeto os processos de mudança social.

Escolhemos o Canadá ${ }^{1}$ como universo de análise por sua formação populacional multicultural e multirracial, bem como por ser uma sociedade com elevado padrão em termos de qualidade de vida e de respeito aos direitos humanos. Neste contexto, consideramos a variedade dos padrões histórico-político-culturais relacionados às experiências de gestão educacional e escolar em que nos chamou a atenção a noção de estudante em situação de risco destacada pela literatura canadense. Por este motivo, realizamos um estudo de caso numa escola pública em Toronto, no período de setembro de 2009 a fevereiro de 2010, com o intuito de apreendermos os sentidos atribuídos aos processos de organização escolar e educacional. A análise não se restringe ao estudo de caso, mas utiliza-se de aspectos nele observados para construir interpretações acerca da organização escolar e educacional canadense, como referência analítica que nos permite oferecer/produzir interpretações que procuram dar sentido aos modos nos quais os atores buscam, por sua vez, dar sentido às suas ações. Vale destacar que as reflexões resultantes das análises conduzem muito mais à abertura de novas questões do que a sínteses conclusivas. 
O estudo nos estimula a refletir a respeito da educação brasileira sem nenhuma pretensão em termos de linearidade comparativa. Consideradas as devidas particularidades de cada sociedade, entendemos que algumas semelhanças nos instigam a refletir a respeito dos rumos previsíveis da sociedade brasileira. A este respeito, Beck (2010, p. 25) esclarece que “(...) cedo ou tarde na história social começam a convergir na continuidade dos processos de modernização as situações e os conflitos sociais de uma sociedade 'que distribui riqueza' com os de uma sociedade 'que distribui riscos'". Entendemos, com isso, que a modernidade parece ter trazido uma situação hibrida entre ambos os tipos de conflitos, levando à existência de sociedades que não poderiam ser chamadas ainda "de risco", mas tampouco podem ser vistas como sociedades cujos conflitos distributivos são apenas de escassez, como, a nosso ver, parece ser o caso do Canadá.

$\mathrm{O}$ debate aqui proposto insere-se num contexto marcado pela partilha internacional dos valores do pluralismo democrático, na perspectiva da interdependência global e da participação ativa na sociedade mundial, em que valores universais a respeito da natureza do ser humano e do comportamento social implicariam em inclusão social e redução das desigualdades. Nesta perspectiva, estratégias de avaliação educacional dão vida a indicadores estatísticos que, por sua vez, levam o Estado a recorrer a categorias de tipos de classes humanas para a administração social.

A noção de risco é por nós destacada e associada à perspectiva da prevenção contra algo institucionalmente indesejado: a marginalização. Assim, entendemos que o que se denomina de inclusão social, contraditoriamente, gera também as categorias de exclusão. As características de indivíduos são organizadas em grupos, sobre os quais são aplicados cálculos de probabilidade que indicam suas perspectivas comportamentais. À noção de risco, portanto, associamos uma forma de governança que define o que significa inclusão e exclusão social, o que é constituído historicamente e que pretendemos compreender ao analisarmos a escola canadense.

\section{Repercussões das políticas educacionais multiculturais no Canadá}

Para compreendermos a questão do enfrentamento das políticas educacionais quanto ao multiculturalismo no Canadá, analisamos alguns dados relativos à diversidade étnico-cultural que tornou o Canadá reconhecido internacionalmente como um dos países mais multiculturais do mundo.

O Canadá conta, em 2010, com população de 34.108,752 habitantes (Statistics Canada, 2010). A mistura de populações (etnias e nacionalidades) teve origem principalmente nos fluxos migratórios decorrentes da Segunda Guerra Mundial, em que os migrantes, que seriam temporários, ficaram nos países hospedeiros por causa da 
falta de emprego em seus países de origem, tornando-se imigrantes; e mais e mais crianças, inclusive nascidas nos países hospedeiros, foram entrando nas escolas, o que se tornou uma questão política mais ampla (Wittek, 1992). Por este motivo, a classificação de grupos adotada pelo Instituto de Estatística do Canadá é mais complexa: baseia-se nas minorias visíveis (visible minority population) relacionadas às procedências. São caracterizados 13 grupos derivados: chineses, sul-asiáticos, pretos, filipinos, latino-americanos, sudeste-asiáticos, árabes, oeste-asiáticos, coreanos, japoneses, minorias visíveis, múltiplas minorias visíveis e não minorias visíveis (referindo-se a indivíduos autoidentificados como aborígenes) (Statistics Canada, 2010).

Como conseqüência, a segregação de filhos de migrantes foi tomada como objeto de atenção na busca da promoção do entendimento internacional e da igualdade de oportunidades de acesso às facilidades educacionais, bem como a oferta de aquisição da língua e cultura dos países de origem para filhos de migrantes (diferentemente do que ocorreu no Brasil, onde apenas recentemente os diferentes segmentos da população vêm sendo objeto de políticas públicas). $\mathrm{O}$ bilinguismo foi apontado como possível solução para assegurar a garantia de direitos e reconhecimento das diferenças. Tudo isso, contraditoriamente, trouxe incoerências inerentes à própria interculturalidade, ao bilinguismo e ao antirracismo.

Os filhos de imigrantes também experimentam impedimentos sociais e econômicos de integração, fazendo persistir o baixo padrão socioeconômico e a própria situação de subclasses. Conforme análise de Schugurensky (2009) sobre os dados do censo canadense, há uma incidência de pobreza familiar chegando aos $41,4 \%$, nas comunidades de origem latino-americanas, a $44,6 \%$ nas comunidades negras, africanas e caribenhas, e a $45,2 \%$ nas comunidades árabes e do oeste asiático, o que, nos três casos, representa aproximadamente o triplo dos $14,4 \%$ registrados nas comunidades de origem europeia no Canadá.

Destacamos aqui que a política educacional canadense é organizada em conformidade com os ministérios de Educação das províncias, não adotando, portanto, uma característica de padronização nacional. Um bom exemplo pode ser observado na questão do bilinguismo que encontra em Ontário uma variante inglesa e em Quebec uma variante francesa, em consideração às primazias das diferentes ondas de colonização e suas respectivas heranças culturais, denotando a política multicultural e pluralista. Esta política incide sobre as chamadas minorias, que têm suas identidades de origem territorial, racial, étnica e religiosa, mantidas e asseguradas, além da cidadania canadense.

Em meio a perfis tão diversos, um dos indicadores nos intriga: o analfabetismo no Canadá é quase inexistente $(0,1 \%$,), mas há forte preocupação com a evasão escolar, particularmente no ensino médio, à qual se associa a noção de estudante em 
situação de risco. No nosso entendimento, a compreensão destes aspectos determina a noção de risco contra o qual se pretende proteger, denotando também o sentido de risco em termos educacionais.

A questão fundamental das bases da miscigenação, que tanto se assenta numa atenção às minorias, quanto numa afirmação de direitos, refere-se, a nosso ver, não apenas à quantidade, mas às condições sociais nas quais os grupos se encontram em termos de uma situação de desvantagem ou discriminação. Concerne explicitamente às relações de poder e, portanto, aos padrões que as desigualdades assumem na distribuição de poder, trazendo reflexos para a vida escolar.

\section{A noção de estudante em situação de risco}

A noção de estudante em situação de risco, tal como difundida pelos órgãos governamentais, nos chamou a atenção por supormos que, numa sociedade tão organizada e oficialmente preocupada com questões sociais relativas à educação, às identidades e à integração cultural, racial e étnica, como a canadense, não encontraríamos tal ênfase nessa noção, haja vista que o Canadá ocupa a quinta melhor posição no Índice de Desenvolvimento Humano (PNUD, 2010). No entanto, o órgão responsável pela organização das escolas de Toronto (Toronto Student School Board, 2006) apresenta expressamente o que entende por semelhante situação: "A vasta maioria dos nossos estudantes de risco é claramente identificável no seu primeiro ano do ensino secundário", referindo-se especialmente a alta proporção de estudantes que: tiveram aproveitamento inferior a $60 \%$ em língua inglesa, ciências ou matemática no último ano do ensino fundamental; estudantes do sexo masculino; aqueles que começaram a escola em idade mais avançada do que a apropriada; aqueles provenientes de bairros de baixa renda; aqueles nascidos no Caribe anglo-hispânico, América Central e Latina, África Oriental; os que falam português, espanhol e somali.

O Toronto District School Board (TDSB, 2009) apresenta dados relativos a este indicador através da seguinte expressão: "Acumulação de créditos - 16 ou mais créditos adquiridos por idade apropriada no Grau 10", indicando que $69 \%$ dos estudantes com 16 anos de idade conseguiram concluir 16 créditos no segundo ano do ensino secundário. ${ }^{2}$ Isso também nos diz que os $31 \%$ restantes não o fizeram, sugerindo, então, os possíveis "drop-outs", ou seja, os estudantes em situação de risco, situação esta contra a qual se colocam políticas específicas.

A ideia de prevenção presente neste conceito é específica quando os alunos já têm 16 anos, o que não significa que antes desta idade não haja o risco de evasão. Todavia, esta ênfase relaciona-se à entrada das pessoas no mercado de trabalho, o que 
é indicativo de que a situação de risco no Canadá tende a ocorrer em faixas etárias bem superiores àquelas em que ocorre no Brasil. ${ }^{3}$

Chama-nos a atenção também a referência às origens africana e latina, bem como aos idiomas afro-asiáticos e latinos, uma vez que identificam claramente a procedência dos estudantes que tendem a ter problemas de evasão. Uma vez considerados em situação de risco, tenderão a ser tratados de forma específica ou com cuidados especiais, o que inclui propensão a serem destinados mais às ESL Schools. ${ }^{4}$ Estas, por sua vez, tendem a concentrar alunos destas origens, o que, entendemos, pode ser interpretado como segregação multicultural.

Em outra perspectiva, que poderíamos denominar de crítica, Portelli, Shields e Vibert (2007) discutem os caminhos em direção a uma educação equitativa ou justa, considerando outros elementos no emprego da noção de situação de risco. Neste sentido, partem da análise das limitações deste termo na abordagem do discurso oficial canadense que, como vimos, a associa ao estudante com baixa expectativa de sucesso escolar ou com outras condições especiais, geralmente ligadas a limitações individuais. Em contraposição, os autores apresentam uma compreensão mais abrangente em que as condições sociais, econômicas, políticas e culturais são relacionadas. Nesta perspectiva crítica, é proposto que professores, estudantes e a comunidade utilizem seu poder para se tornarem agentes positivos de mudança. Assim, sugerem uma alternativa prática mais adequada em que os sujeitos escolares desenvolvem relações solidárias e avaliam criticamente seus próprios contextos, tendo em conta critérios da equidade e justiça social.

Dei (1996), em estudo desenvolvido sobre estudantes considerados em situação de risco, demonstra como estes se queixam sobre o ambiente escolar e não escolar e como percebem a falta de oportunidades para realizar seus sonhos e ambições. Conforme o autor, particularmente para os estudantes das minorias, as nuanças do seu deslocamento de identidades e cruzamentos de marginalidades são exacerbadas pela falta de reconhecimento do sistema educacional de que todos entram nas salas de aulas com um reservatório próprio de capital político e cultural.

Quando os estudantes das minorias, por exemplo, utilizam este capital para resistir às normas e valores hegemônicos e estruturas patriarcais, eles percebem serem ainda mais subordinados. Os alunos são então rotulados como desviantes, crianças-problema e jovens em risco. (Dei, op. cit., p. 79)

A concepção de estudante em situação de risco naquele país, apesar da clara adoção de uma perspectiva inclusiva relativa à diversidade sociocultural, nos faz ver que a questão econômica se explicita no discurso oficial através de um investimento massivo em programas de reintegração. A literatura canadense a respeito assume as diferenças étnico-culturais em consideração, principalmente, à diversa conformação 
de origens e à questão racial. No entanto, ao demarcar as bases da inclusão social, ao mesmo tempo e contraditoriamente, esclarece que as diferenças de origem geram diferentes comportamentos por parte dos estudantes, definindo os passíveis de exclusão, o que incide diretamente na orientação das políticas governamentais concernentes. Dessa forma, as análises mencionadas, bem como as políticas governamentais nos parecem segregacionistas. Os riscos são socialmente reconhecidos e, assim, são previstos os atores e as instâncias envolvidas, numa relação de causa e efeito, "com ameaças e fenômenos nocivos inteiramente alheios no que diz respeito à dimensão social, de conteúdo, espacial ou temporal" (Beck, 2010, p. 33).

Uma melhor explicitação do que estamos querendo sublinhar - a questão do multiculturalismo e do tratamento do risco na educação por escolas canadenses pode ser obtida por meio dos dados que apresentaremos em seguida, fruto de pesquisa realizada em uma escola deste país. Assim, a noção de estudante em situação de risco poderá ser mais bem compreendida a partir dos dados da realidade em termos de sua análise, que denota a produção de desigualdades socioeducacionais, apesar de inserida num contexto político e cultural expressamente antirracista e multicultural.

\section{A rotina escolar canadense}

Visando captar elementos da rotina escolar canadense, com foco no tratamento do multiculturalismo e da questão dos estudantes em risco, realizamos um estudo etnográfico numa escola de ensino médio de Toronto. A coleta de dados compreendeu sessões de observação da rotina da escola, aplicação de um questionário aos professores e equipe pedagógica, bem como a realização de entrevistas com a equipe gestora e com os professores que atuavam em programas específicos ${ }^{5}$ de atendimento aos jovens em situação de risco - ou seja, jovens considerados em situação de risco de abandonarem a escola, ou já na condição de retorno após terem evadido temporariamente. ${ }^{6}$

Os questionários continham livre associação de palavras tais como multiculturalismo, democracia, justiça, estudante em situação de risco, bem como questões abertas que focavam as ações da escola relacionadas à diversidade cultural e estudantes em situação de risco. As entrevistas seguiam roteiro semelhante, com maior ênfase nas questões abertas e nas particularidades inerentes aos trabalhos desenvolvidos pelos entrevistados. As observações incidiram sobre a rotina e organização escolar, com foco nas questões referentes ao multiculturalismo, à diversidade e aos estudantes em situação de risco. Diversos documentos do Toronto District School Board e do Ontario Ministry of Education foram também analisados. Considerando a dimensão e propósito deste artigo, selecionamos apenas alguns aspectos que nos apoiam nesta análise, particularmente obtidos a partir das representações dos sujeitos. 
Os dados da escola observada referentes a 2009 indicam a matrícula de 705 alunos, dos quais 437 (62\%) têm como primeira língua outra que não o inglês. Destes, cerca de 10\% (77 estudantes) têm como primeira língua o espanhol ou o português.

O Programa "Inglês como Segunda Língua" (English as a Second Language ESL) deveria ser oferecido em todas as escolas, mas, de fato, algumas delas não o oferecem, a exemplo das que exibem a marca zero de estudantes aprendentes de inglês (English Language Learners). Enfatizamos que os estudantes que chegam ao Toronto District School Board, cujas avaliações diagnósticas indicam a necessidade de ESL, são então encaminhados para as escolas que oferecem o programa, conhecidas como ESL Schools. Encontramos aí uma sutil diferenciação, confirmada em diversos momentos de entrevistas, a exemplo de uma professora que disse que algumas escolas não querem receber "aquele tipo de estudante", denotando, pela diferenciação, a existência de um tratamento discriminatório.?

O currículo das escolas secundárias canadenses baseia-se no sistema de créditos, em que o estudante regular faz 4 créditos por semestre ou 8 por ano, devendo completar 30 créditos para obter a graduação, dispostos em conformidade com suas opções. Além das disciplinas, as escolas oferecem os chamados "clubes", voluntariamente propostos por professores, a exemplo do Clube de Direitos Humanos, o de xadrez, música, esportes, cujos encontros ocorrem nos intervalos do almoço ou após o horário de aulas. Conforme o TDSB, o currículo oferece muitas opções porque "é o sistema escolar mais multilíngue e multicultural do mundo", visto que recebe estudantes que começam a aprender inglês quando chegam ao Canadá e entram na escola.

Entre os dados coletados, enfatizamos a compreensão da noção estudante em situação de risco, mas almejamos também o entendimento mais amplo de risco social. Os professores associaram a risco social palavras como pobreza, más condições socioeconômicas, justiça, perigo à sociedade. Apenas um relacionou à evasão escolar (drop-out) e ainda à frustração e depressão de alunos desengajados do sistema, referindo-se a estudante em situação de risco.

Já as associações feitas especificamente à expressão estudante em situação de risco foram as seguintes: falha no processo de escolarização, o que incluiu reprovação nas disciplinas, falhas em geral, absenteísmo e saída da escola ou risco de sair dela; ainda acrescentaram falta de suporte familiar, acomodação, individualismo, pressão/estresse emocional e social em casa.

Entre as questões abertas, perguntamos o que pode ser feito para ajudar estudantes em situação de risco, bem como quais as soluções que já são oferecidas pela escola. As respostas às duas perguntas foram similares, o que interpretamos como concordância dos sujeitos com os encaminhamentos oferecidos pela escola. Estes 
enfatizaram programas que oferecem suporte aos estudantes, sendo que um deles citou especificamente o "clube do café da manhã" (que atende cerca de 40 alunos), como resposta ao problema da fome, mas também trataram da tutoria por pares e programas alternativos; citaram também a ação docente de entendimento e ajuda; o encaminhamento destes alunos para especialistas, o oferecimento de uma atenção mais individual e concentração em conduzi-los nas disciplinas e, ainda, a questão curricular como algo que deve ser repensado em função das diferenças. Um professor comentou que não há nenhuma solução real, questionando os limites de ação da escola e apontando as questões sociais estruturais. Outro citou um currículo menos branco, criticando a racialização.

Os sujeitos caracterizaram a clientela da escola referindo-se ao baixo padrão socioeconômico, problemas familiares e pessoais, desmotivação, muito estresse e riscos de saúde. A expressão diversa apareceu relacionada à variedade de estudantes e comunidades, o que dificulta a especificação na descrição, conforme um dos professores. A expressão multicultural apareceu apenas uma vez. Seguem algumas destas respostas:

A clientela escolar vem de origens socioeconomicamente marginalizadas com histórias de eventuais abusos e violência que levam a tendências autodepreciativas;

(Os alunos são) Desmotivados, pobres, não têm suficiente suporte em casa;

A maioria de nossos alunos tem baixo rendimento... Eu não sei sobre suas comunidades. Há um grande número de comunidades;

Muitos novos canadenses;

Quando perguntamos sobre o significado da diversidade cultural para a organização das atividades da escola, as respostas incluíram ações afirmativas, como: a contribuição com diferentes paradigmas de pensamento e experiências que poderiam ser excluídos, de outra maneira, de uma situação homogeneizada, ou precisa ter certeza de que todos são incluídos e representados, além de estimulo à tolerância, aceitação de todas as culturas. Encontramos também algumas posições críticas, no sentido de questionarem a efetivação da diversidade cultural: existem algumas atividades que são particularmente subscritas por algumas culturas; parece que os alunos tendem a ficar com seu próprio grupo cultural; atividades extracurriculares na nossa escola não são muito frequentadas.

Citam o isolamento de alguns grupos culturais, afirmando que nem sempre há interesse ou aceitação da diversidade, o que confirmamos em nossas observações no dia a dia da escola, em que grupos de alunos de mesma procedência se reúnem para conversar nos corredores, inclusive recorrendo às suas línguas pátrias.

A expressão multiculturalismo é associada à diversidade e variedade de origens, linguagens, culturas, raças, comidas, bem como a comportamentos como respeito e tolerância. A palavra foi ainda relacionada ao mosaico, por dois professores, 
em alusão a uma figura de linguagem comum, que classifica o Canadá como sendo formado por pedaços independentes que constituem um todo.

Um dos professores entrevistados trabalha com o chamado Continuous Intake Co-op (CIC)/ Alternative Programs ${ }^{8}$ e quando perguntei sobre o multiculturalismo e as diferenças sociais e culturais, ele explicou que, na América do Norte, todas as pessoas são imigrantes. Assim, ele entende que o problema da desigualdade social é anterior às ondas de imigração mais recentes (a partir dos anos de 1960). Ele diz que não podemos rotular os imigrantes como a causa dos problemas sociais e contou de sua família que veio para o Canadá em 1950. Quando chegaram àquele país, começaram a trabalhar com pessoas da mesma origem e formaram novas comunidades de imigrantes. Ele explica que os imigrantes dos anos de 1950 eram principalmente da Europa, mas a onda de imigração iniciada na década de 1960 vem de outros lugares como Índia, China, Somália, Bangladesh, Paquistão, Afeganistão e outros (algumas ex-colônias britânicas) e comenta que um grande número de refugiados também veio para o Canadá. A este respeito Beck (2010, p. 16) esclarece que as

(...) "ameaças sociais" e seu potencial cultural e político são apenas um lado da sociedade de risco. O outro lado passa a ser visível quando são inseridas no centro da questão as contradições imanentes entre modernidade e contramodernidade presentes no plano geral da sociedade industrial: por um lado, a sociedade industrial é definida como sociedade de grandes grupos, no sentido de uma sociedade de classes ou camadas sociais, e isso ontem, hoje e para todo o sempre. Por outro lado, as classes sociais permanecem dependentes da validade das culturas e tradições sociais de classe, que são justamente destradicionalizadas ao longo da modernização do Estado de Bem-Estar Social (...).

Os dados coletados na escola parecem confirmar que, entre os resultados da política educacional multicultural canadense, há segregação, apesar dos bons indicadores educacionais do país. A seguir, apresentaremos alguns dados da realidade brasileira, com o intuito de fornecer elementos para a compreensão da análise que aqui nos propomos a tecer, ainda que com a devida ressalva relativa às restrições para a interpretação dos fenômenos em foco na perspectiva comparativa qualitativa. Os dados, portanto, pretendem desvelar algumas contradições das políticas multiculturais que, apesar de bem intencionadas, são assentadas em fundamentos equivocados para a real promoção de políticas educacionais de igualdade social.

\section{Considerações acerca da realidade brasileira}

No Brasil, o sistema educacional nacional, diferentemente do que ocorre no Canadá, estabelece as normas globais sobre as quais os estados e municípios devem se fundamentar. Esta política é adotada na perspectiva de assegurar um padrão mínimo de direitos e deveres no quesito educação para todos os brasileiros, 
independente de credo, etnia, origem, configurando o que poderíamos chamar de respeito ao multiculturalismo. No entanto, apesar da chamada flexibilização curricular adotada com vistas às adequações regionais e locais, principalmente a partir dos Parâmetros Curriculares Nacionais (PCNs) (Brasil, 1998), as diferenças nos resultados educacionais são visíveis.

A Pesquisa Nacional por Amostra de Domicílios (PNAD) de 2008 (IBGE, 2010) encontrou no Brasil 92.003 milhões de brancos, 12.987 milhões de pretos, $83.196 \mathrm{mi}-$ lhões de pardos, 1.101 mil amarelos e 536 mil indígenas. Somando pretos e pardos, temos quase $50 \%$ da população. Os dados da PNAD relativos a 2008 revelam ainda que a taxa de analfabetismo das pessoas de 15 anos ou mais de idade foi estimada em 10,0\%. A taxa de analfabetismo funcional foi estimada em 21,0\% (30 milhões). No entanto, o índice de analfabetismo entre jovens negros era, em 2008, duas vezes maior que entre brancos, segundo o Instituto de Pesquisas Aplicadas (Ipea) (Acordacidade, 2010). No ensino médio, o número de jovens brancos que frequenta a escola é 44,5\% maior em comparação ao de negros.

Os fluxos migratórios trouxeram consequências para a desigualdade social, encontrando-se na região Sul uma população predominante de brancos (origem europeia, especialmente no século XIX); no nordeste, de pardos e pretos (origem africana que trabalhou nos engenhos de cana-de-açúcar); de pardos, no norte (origem indígena). Pochmann (2004, p. 7) esclarece que o processo tardio de abolição da escravatura implicou a "transição extremamente conservadora para o assalariamento, através da imigração de mão de obra europeia e asiática, deixando a população negra excluída da possibilidade de imediata integração pelo emprego salarial". Assim, o país foi um dos que mais rápido expandiu sua economia no mundo, sem obter, todavia, resultados consideráveis no âmbito social.

Estes dados nos conduzem a refletir não apenas a respeito das origens da desigualdade e exclusão, mas de suas consequências no cenário educacional, no qual destacamos os diferentes sentidos atribuídos à noção de risco, uma vez que esta se materializa na forma de políticas públicas a partir dos indicadores de exclusão. Conforme Popkewitz e Lindblad (2001, p.137), é "uma categoria importante nas estatísticas que relacionam a governança de educação com a inclusão e a exclusão". Queremos dizer que a desigualdade socioeconômica brasileira, marcada pela mistura de populações e etnias, incide profundamente na organização da educação.

A única minoria amplamente identificada no Brasil é a dos indígenas, cuja população não é exata. A multidão de pretos e pardos, em sua maior parte pobres e marginalizados, não pode ser definida como tendo outra identidade territorial que não a brasileira. Ambas são subsumidas sob a estrutura econômico-social brasileira. 
E, sobre esta diferença, as políticas adotadas ainda não se materializam como efetiva igualdade e universalização do acesso à educação com qualidade.

O Brasil, portanto, diferentemente do Canadá, construiu sua noção de estudante em situação de risco à imagem da exploração de uma classe por outra e exige muito pouco em termos de cidadania e princípios enquanto definição de risco contra o qual se almeja proteger um estudante para que este seja incluído socialmente. Assim, esta concepção é confundida com a de criança de risco (Menezes \& Brasil, 1998), que trabalha desde cedo, vive nas ruas, é sujeita a todo tipo de irregularidades que qualquer pessoa humana não deveria correr. Esta tem que ser prevenida e eliminada por parte das demais políticas públicas, para que as políticas educacionais possam se ater ao estudante na escola.

\section{Considerações finais}

Nosso propósito de caracterizar implicações das políticas multiculturais na educação e na escola, bem como de conhecer as concepções e experiências relacionadas, nos conduziu a uma análise da escola (mediante os depoimentos obtidos dos sujeitos investigados e observações realizadas numa escola canadense) pautada na influência dos padrões histórico-político-culturais sobre as políticas adotadas no sentido da igualdade e da universalização do acesso à educação.

As concepções e explicações dos fenômenos educativos fornecidas sinalizam certa consciência crítica, ao mesmo tempo em que compreensão e concordância relativas às políticas educacionais adotadas no Canadá. Dessa forma, compreendemos que a noção de estudante em situação de risco, naquele país, foi se consolidando a partir das correntes internacionais de migração resultantes do processo da globalização, levando a uma política preventiva com foco em estudantes de nível secundário. Lá, a noção de estudante em situação de risco baseia-se na idade de 16 anos como referência para que cada indivíduo seja incluído socialmente.

A educação e a escolarização, em ambos os países, contribuem na construção de identidades, ora assegurando e reforçando os laços étnico-culturais dos estudantes como decorrência da política multicultural (Canadá), ora reforçando as diferenças de cunho socioeconômico que demarcam as diferenças entre os estudantes (Brasil). Enfatizamos que a escola brasileira dispõe, hoje, de mecanismos que permitem que ela seja democrática; o sistema social, no entanto, não.

Assim, independentemente das fases do processo de modernização em que se encontram tanto o Brasil como o Canadá, os conflitos distributivos em torno da riqueza socialmente produzida, marcados pelas diferenças de origem relativas aos processos históricos vividos, estarão presentes, e o pensamento e a ação das pessoas 
dominadas pela carência material ocuparão lugar de destaque por conta da "ditadura da escassez" (Beck, 2010, p. 24).

Esta é nossa preocupação ao analisarmos as implicações educacionais das políticas multiculturais marcadas pelo respeito à diversidade cultural. Enfatizamos nossa compreensão de que a política educacional multicultural não assegura mais democracia.

\section{Notas}

1. Trata-se de estudo desenvolvido durante a realização de estágio de pós-doutoramento que serviu de parâmetro comparativo para pesquisa sobre a mesma temática que temos desenvolvido no Brasil.

2. Esclarecemos que o currículo das escolas secundárias canadenses baseia-se no sistema de créditos, em que a cada ano o estudante regular faz 4 créditos por semestre ou 8 por ano, devendo cursar 30 créditos para obter a graduação.

3. De fato, aplicando o mesmo indicador, nossos dados mostram que, em 2008, havia 4,5 milhões de pessoas ocupadas com idade de 5 a 17 anos (IBGE, 2010a).

4. ESL Schools são as escolas assim conhecidas por ofertarem o Programa "Inglês como Segunda Língua", o que oficialmente ocorreria em todas as escolas, mas, efetivamente, algumas delas não o oferecem.

5. Programas que oferecem suporte aos estudantes de risco, como o "clube do café da manhã", a tutoria por pares, programas de cooperação escola-empresa, encaminhamento de alunos a especialistas, entre outros.

6. No total, entrevistamos 23 sujeitos.

7. É redundante informar que a escola pesquisada oferece o ESL.

8. Cooperação de Ingestão Contínua - Programas Alternativos: inclui cooperação com empresas em que os alunos trabalham e ganham créditos ao invés de salário e para alunos que abandonaram a escola para trabalhar e retornam a ela, como condição para manterem seus empregos.

\section{Referências}

ACORDA CIDADE. Analfabetismo entre jovens negros é duas vezes maior. 2009. Disponível em: <http://www.acordacidade.com.br/noticias/1753/educacao/analfabetismo_ entre_jovens_negros_e_2_vezes_maior.html> Acesso em: 5 fev. 2010.

BECK, U. Sociedade de risco. Trad. de Sebastião Nascimento. São Paulo: Editora 34, 2010.

BRASIL. Ministério da Educação. Secretaria de Educação Fundamental. Parâmetros Curriculares Nacionais: temas transversais; pluralidade cultural. Brasília, DF: MEC/ SEF, 1998.

CALIMAN, G. Estudantes em situação de risco e prevenção. Ensaio: Avaliação e Políticas Públicas em Educação, Rio de Janeiro, v. 14, n. 52, p. 383-396, jul./set. 2006. 
DEI, G. Anti-racism education: theory and practice. Halifax: Fernwood, 1996.

INSTITUTO BRASILEIRO DE GEOGRAFIA E ESTATÍSTICA (IBGE). PNAD 2008. Disponível em: <www.ibge.gov.br/home/estatistica/populacao/condicaodevida/ indicadoresminimos/sinteseindicsociais2008> Acesso em: 4 jan. 2010.

MALET, R. Do Estado-nação ao espaço-mundo: as condições históricas da renovação da educação comparada. Educação \& Sociedade, Campinas, v. 25, n. 89, p.1301-1332, set./ dez. 2004.

MENEZES, D.M.A.; BRASIL, K.C.T. Dimensões psíquicas e sociais da criança e do adolescente em situação de rua. Psicologia: Reflexão e Crítica, Porto Alegre, v. 11, n. 2, p. 327-344, 1998.

POCHMANN, M. Proteção social na periferia do capitalismo: considerações sobre o Brasil. São Paulo em Perspectiva, São Paulo, v. 18, n. 2, p. 3-16, abr./jun. 2004.

POPKEWITZ, T.; LINDBLAD, S. Estatísticas educacionais como um sistema de razão: relações entre governo da educação e inclusão e exclusão sociais. Educação $\mathcal{E}$ Sociedade, Campinas, v. 22, n. 75, p. 75-111, ago. 2001.

PORTELLI, J.; SHIELDS, A.; VIBERT, C. Toward an equitable education: poverty, diversity and students at risk. Toronto: Ontario Institute for Studies in Education; Centre for Leadership \& Diversity, 2007.

PROGRAMA DAS NAÇÕES UNIDAS PARA O DESENVOLVIMENTO (PNUD). Relatório de Desenvolvimento humano. [s.d.]. Disponível em: <http://hdr.undp.org/en/ data/trends> Acesso em: 28 dez. 2010.

SCHUGURENSKY, D. El Informe Brown y la pregunta del cuarenta por ciento. In: MANTILLA, D.; SCHUGURENSKY, D.; SERRANO, J.F. (Org.). Cuatro de cada diez: juventud de habla hispana y abandono escolar en Toronto. Toronto: Lared/Transformative Learning Centre; OISE/UT, 2009. p. 1-13.

STATISTICS CANADA. Visible minority population and population group reference guide, 2006 census. Disponível em: <http://www12.statcan.ca/census-recensement/2006/ref/ Rp-guides/visible_minority-minorities_visibles-eng.cfm\#Classifications> Acesso em: 31 out. 2010.

TORONTO DISTRICT SCHOOL BOARD (TDSB). The Grade 9 Cohort Study: a fiveyear analysis, 2000-2005. Research Today, Toronto, v. 2, n. 1, Fall 2006.

TORONTO DISTRICT SCHOOL BOARD (TDSB). The Grade 9 Cohort of Fall 2002: a five year cohort study 2002-/2007. Research Today, Toronto, v. 4, n. 1, Winter 2009. (Prepared by Robert S. Brown, 2009). 
WITTEK, F. The historical and international context for current action on intercultural education. In: REID, E.; REICH, H. Breaking the boundaries: migrant workers' children in the EC... Clevdon: Multilingual Matters, 1992.

Recebido em 3 de janeiro de 2011.

Aprovado em 20 de janeiro de 2012. 